\title{
The Clock-in-the-Box, a brief cognitive screen, is associated with failure to return home in an elderly hospitalized sample
}

\author{
Colleen E Jackson ${ }^{1-3}$ \\ Laura J Grande ${ }^{1-3}$ \\ Kelly Doherty' \\ Elizabeth Archambault' \\ Brittany Kelly' \\ Jane A Driver ${ }^{1,4}$ \\ William P Milberg ${ }^{1,2,5}$ \\ Regina McGlinchey ${ }^{1,2,5}$ \\ James L Rudolph ${ }^{6,7}$ \\ 'Geriatric Research, Education \\ and Clinical Center, Department \\ of Veterans Affairs (VA) Boston \\ Healthcare System, Boston, MA, \\ ${ }^{2}$ Translational Research Center for \\ TBI and Stress Disorders, Department \\ of Veterans Affairs (VA) Boston \\ Healthcare System, Boston, MA, \\ ${ }^{3}$ Department of Psychiatry, Boston \\ University School of Medicine, \\ Boston, MA, ${ }^{4}$ Department of Medicine, \\ Harvard Medical School, Boston, MA, \\ ${ }^{5}$ Department of Psychiatry, Harvard \\ Medical School, Boston, MA, ${ }^{6}$ Center \\ of Innovation in Long Term Services \\ and Supports, Department of Veterans \\ Affairs (VA) Providence Medical \\ Center, Providence, RI, ${ }^{7}$ Department \\ of Medicine, Warren Alpert School \\ of Medicine of Brown University, \\ Providence, RI, USA
}

This article was published in the following Dove Press journal:

Clinical Interventions in Aging

22 November 2016

Number of times this article has been viewed

Purpose: Cognitive screening upon hospital admission can provide important information about the patient's ability to process information during the inpatient stay. The Clock-in-theBox (CIB) is a rapidly administered cognitive screening measure which has been previously validated with cognitive screening and neuropsychological assessments. The purpose of this study is to demonstrate the predictive validity of the CIB for discharge location among a sample of older medical inpatients.

Patients and methods: Hospitalized Veterans ( $\mathrm{N}=218)$, aged 55 years and older, were recruited on the day after admission after they gave their consent. These participants completed the CIB, the Montreal Cognitive Assessment, and self-report measures of daily functioning. Using logistic regression models, the bivariable and multivariable impact of the cognitive screening and functional assessments were examined for their ability to predict whether the participants did not return home after hospitalization (eg, admission to subacute rehabilitation facilities or nursing facilities).

Results: The participants were older (mean $71.5 \pm 9.5$ years) and predominantly male $(92.7 \%)$. The CIB score was independently associated with discharge to locations other than home (odds ratio $=0.72,95 \%$ confidence interval $=0.60-0.87, P=0.001)$ and remained associated after adjusting for demographics, prehospitalization functional abilities, and Montreal Cognitive Assessment score (adjusted odds ratio $=0.55,95 \%$ confidence interval $=0.36-0.83, P=0.004$ ).

Conclusion: The current evidence, combined with its brevity and ease of use, supports the use of the CIB as a cognitive screen for inpatient older adults, in order to help inform clinical treatment decisions and discharge planning.

Keywords: cognition, screening, aging, hospitalization, care transition

\section{Introduction}

Hospitalization is a sentinel event in the life trajectory of an older person, ${ }^{1}$ and there are multiple factors influencing discharge planning, including demographics, social support, medical comorbidity, previous functional deficits, and cognitive function. Although recovery from medical illness and physical injury is often considered paramount during the inpatient stay, evidence suggests that cognitive functioning is also a salient issue impacting the recovery postdischarge. ${ }^{2,3}$

Reduced cognitive performance is often underdiagnosed in inpatient settings; ${ }^{4-6}$ yet, it has been linked to increased risk of hospitalization and longer inpatient hospital stays,${ }^{7}$ discharge to a facility rather than home, ${ }^{8}$ and greater dependence in activities of daily living (ADL). ${ }^{9}$ This association between cognitive function and recovery after hospitalization highlights the importance of routine inpatient cognitive screening to facilitate inpatient care and discharge planning. 
Routine inpatient cognitive screening is limited by the time-pressured clinical environment and the training necessary to administer and score the cognitive assessments. Although there are multiple screening measures available, the most useful cognitive screening measure is one that engages multiple cognitive processes, especially executive function (eg, planning, organization) $\cdot{ }^{10}$ The assessment of executive functioning during inpatient assessment is particularly desirable, as performance on executively demanding tasks is predictive of function upon discharge. ${ }^{11}$ Although multiple bedside screening measures exist, many are limited in the types of cognitive domains assessed and/or the length of the assessment. The Clock-in-the-Box (CIB) requires 1-2 minutes for administration and is a validated screening measure assessing working memory and executive functions. ${ }^{12}$ The CIB has been compared to cognitive screening instruments, as well as more intensive neuropsychological assessments, and has demonstrated strong reliability and validity in multiple patient populations..$^{13,14}$

The primary aim of the current study was to examine the association between cognitive performance on the CIB and discharge to locations other than home (eg, subacute rehabilitation facilities, nursing facilities) in a sample of hospitalized older adults. Given previous literature demonstrating that cognitive impairment is a predictor of placement following hospitalization, ${ }^{15}$ we hypothesized that better inpatient CIB score would be positively associated with discharge to home. We also conducted secondary analyses in order to assess the relation between demographic, social, medical, and functional characteristics potentially affecting discharge, and discharge to locations other than home.

\section{Methods}

This study was approved by the Department of Veterans Affairs (VA) Boston Healthcare System Institutional Review Board. All participants provided written informed consent.

\section{Study participants}

Patients admitted for inpatient care at a tertiary VA medical center in the northeast US between January 2013 and March 2014 were approached for participation. Recruitment and assessment were completed by trained study staff, and participants completed the study measures in their hospital room on the morning after hospital admission. Participants were included if they were communicative, English-speaking, 55 years or older, and had sufficient vision and motor abilities to complete study enrollment. Participants were excluded if they were admitted for detoxification or hospice, or could not participate in the cognitive testing due to cognitive impairment, sensory impairment, or delirium.

\section{Assessment methods}

Data on age, sex, race, education, marital status, living situation, alcohol use (drinks per week), and tobacco use (current use) were collected from the participants. In order to assess functional independence before their hospitalization, participants were asked whether they received in-home services (visiting nurse, homemaker, health aid) or often depended on another person for assistance.

Discharge location (ie, home, skilled nursing facility, nursing home), prior diagnosis of dementia, and information necessary to complete the Charlson comorbidity index ${ }^{16}$ were collected from the electronic medical record.

Participant mood was assessed using the Geriatric Depression Scale-Short Form, a 15-item measure of depressive symptoms validated in older adults. ${ }^{17}$ Retrospective assessment of prehospitalization functional abilities was completed using the Katz basic ADL $^{18}$ and Lawton-Brody instrumental ADL (IADL) scales. ${ }^{19}$ Assessment of basic ADL included bathing, dressing, toileting, independent transfer, continence, and eating; IADL assessment included the ability to use a telephone, travel, shop, prepare meals, complete housework, manage medications, and manage money. ADL total scores ranged from 6 to 18; higher scores reflected better functioning. IADL total scores ranged from 7 to 21 ; lower scores reflected better functioning. Impaired performance was determined using a cut-off score of $<17$ (ADL) or $>9$ (IADL). ${ }^{20}$

The CIB and Montreal Cognitive Assessment (MoCA $)^{21}$ were used to assess cognitive functioning. The CIB is based on a standard clock drawing task with an additional working memory component. Participants are provided with an $8.5 \times 11$ sheet of paper with four typed directions: 1 ) In the blue box on the next page, 2) Draw a picture of a clock, 3) Put in all the numbers, 4) Set the time to ten after eleven. After the participant reads and acknowledges understanding the instructions, he/she returns the sheet and is provided with an $8.5 \times 11$ response sheet oriented in the horizontal position. The response sheet has a colored box (yellow, red, green, and blue) in each quadrant and is oriented such that the blue box is in the right lower quadrant. Once the participant indicates that he/she understands the directions, no additional information is provided and the participant is not allowed to refer back to the instructions. The CIB is scored on a $0-8$ point scale for the following criteria: drawing is located in the blue box, object resembles a clock, numbers 1-12 are included, numbers are 
placed in correct order, numbers are approximately evenly spaced, the correct time is set, the clock is of appropriate size, and hand origin and length are correct. The total score includes two separate subscale scores (the first four points linked to the Working Memory subscale and the second four points to the Planning/Organization subscale); higher scores reflect better performance. The CIB requires approximately 2 minutes to administer, and this measure has demonstrated strong reliability and predictive validity across a number of clinical studies. ${ }^{13,14,22}$

The MoCA is a 30-point cognitive measure assessing verbal learning and memory, visuospatial functioning, executive abilities, language, and orientation; higher scores reflect better performance. ${ }^{21}$ The MoCA requires approximately 10 minutes for administration and scoring.

\section{Statistical methods}

All statistical analyses were completed using STATA 11.0.23 Participants were excluded from the current analyses if they were experiencing delirium at the time of assessment. Also, given an interest in return to the home environment, we excluded participants initially admitted from a skilled nursing facility.

We planned to examine the association between individual demographic, clinical, cognitive, and functional variables and discharge home, using bivariable logistic regression. Variables with a trend toward significance $(P<0.20)$ and a potential confounding relationship were selected for inclusion in multivariable models. We anticipated significant collinearity between the measures of cognition and function. Therefore, in the event that ADL and IADL impairment both met the criteria for inclusion in multivariate models, we planned to include ADL score as this was more closely associated with discharge home. We completed z-transformations of CIB and MoCA scores in order to allow for comparison between the two in the same units of change. In order to investigate the unique and combined associations between cognitive performance and discharge home, we ran four separate multivariate regression models: 1) CIB total score alone, 2) MoCA total score alone, 3) CIB and MoCA scores, and 4) CIB subscale scores.

\section{Results}

See Table 1 for demographic information. Participants were primarily male, Caucasian, and well educated; average participant age was 71.4 (standard deviation $[\mathrm{SD}]=9.4$ ) years. Please see Table S1 for CIB total score age and education normative values.
Table I Participant characteristics

\begin{tabular}{|c|c|}
\hline Characteristics & $\mathbf{N}=218$ \\
\hline \multicolumn{2}{|l|}{ Demographics } \\
\hline Age, $M(S D)$ & $71.5(9.5)$ \\
\hline Male, n (\%) & $202(92.7 \%)$ \\
\hline Non-White, n (\%) & $18(8.3 \%)$ \\
\hline \multicolumn{2}{|l|}{ Education, n (\%) } \\
\hline$<12$ years & $36(16.5 \%)$ \\
\hline High school graduate & $52(23.9 \%)$ \\
\hline$>12$ years & $130(59.6 \%)$ \\
\hline \multicolumn{2}{|l|}{ Social support } \\
\hline \multicolumn{2}{|l|}{ Marital status, n (\%) } \\
\hline Married/partnered & II 5 (52.7\%) \\
\hline Single & $31(14.2 \%)$ \\
\hline Divorced & $47(21.6 \%)$ \\
\hline Widowed & $24(11.0 \%)$ \\
\hline Living alone & 77 (35.3\%) \\
\hline Receives assistance & 124 (56.9\%) \\
\hline \multicolumn{2}{|l|}{ Medical comorbidity } \\
\hline Charlson Comorbidity Index, M (SD) & $5.4(3.0)$ \\
\hline Geriatric Depression Scale, M (SD) & $4.8(3.6)$ \\
\hline Active smoker, n (\%) & $36(16.5 \%)$ \\
\hline Active alcohol use, n (\%) & 91 (4I.7\%) \\
\hline \multicolumn{2}{|l|}{ Cognitive ability } \\
\hline Previous diagnosis of dementia, $\mathrm{n}(\%)$ & $4(1.8 \%)$ \\
\hline CIB total, $M(S D)$ & $5.5(1.7)$ \\
\hline CIB Memory subscale, $M(S D)$ & $3.1(1.0)$ \\
\hline CIB Planning/Organization subscale, M (SD) & $2.4(\mathrm{I} .0)$ \\
\hline Montreal Cognitive Assessment, M (SD) & $20.3(3.9)$ \\
\hline \multicolumn{2}{|l|}{ Functional ability } \\
\hline ADL score, $M(S D)$ & $9.1(2.4)$ \\
\hline ADL impairment, $\mathrm{n}(\%)$ & 27 (12.4\%) \\
\hline IADL score, M (SD) & $17.5(1.2)$ \\
\hline IADL impairment, n (\%) & $102(46.8 \%)$ \\
\hline \multicolumn{2}{|l|}{ Outcome } \\
\hline Discharge home, $\mathrm{n}(\%)$ & $182(83.5 \%)$ \\
\hline
\end{tabular}

Abbreviations: $A D L$, activities of daily living; $C I B$, Clock-in-the-Box; IADL, instrumental activities of daily living; $M$, mean; SD, standard deviation.

CIB total score and subscale scores (Working Memory, Planning/Organization) were highly correlated with MoCA total score ( $r=0.57,0.50$, and 0.50 , respectively; $P<0.001$ for all). Figure $\mathrm{S} 1$ depicts the distribution of the MoCA stratified by CIB score. Partial correlation between CIB total score and MoCA, adjusting for age and education, remained significant $(r=0.23, P<0.001)$.

Bivariable analyses identified the associations between age, non-White race, CIB total and subscale scores, MoCA score, and prehospitalization ADL and IADL functioning, with discharge to a location other than home (Table 2).

Multivariate logistic regressions, adjusting for age and race, revealed that $\mathrm{z}$-transformed CIB total score (adjusted odds ratio $[\mathrm{aOR}]=0.59,95 \%$ confidence interval $[\mathrm{CI}]=0.41-0.84, P=0.003)$ and $\mathrm{ADL}$ function $(\mathrm{aOR}=0.74$, 
Table 2 Characteristics associated with discharge to location other than home

\begin{tabular}{lll}
\hline Demographics & $\begin{array}{l}\text { Unadjusted } \\
\text { OR }(95 \% \mathrm{CI})\end{array}$ & P-value \\
\hline Age (per year) & $\mathrm{I} .03(0.99, \mathrm{I} .07)$ & 0.135 \\
Male & $\mathrm{I} .77(0.54,5.84)$ & 0.348 \\
Non-White & $2.10(0.70,6.30)$ & 0.187 \\
Education & $\mathrm{I} .09(0.67, \mathrm{I} .77)$ & 0.723 \\
Active tobacco use & $\mathrm{I} .27(0.5 \mathrm{I}, 3.18)$ & 0.605 \\
Active alcohol use & $0.65(0.3 \mathrm{I}, \mathrm{I} .38)$ & 0.265 \\
Married & $0.76(0.37, \mathrm{I} .57)$ & 0.464 \\
Living alone & $\mathrm{I} .20(0.58,2.5 \mathrm{I})$ & 0.624 \\
Receives assistance & $0.72(0.35, \mathrm{I} .47)$ & 0.363 \\
Charlson Comorbidity Index & $\mathrm{I} .03(0.9 \mathrm{I}, \mathrm{I} .16)$ & 0.619 \\
Geriatric Depression Scale & $\mathrm{I} .03(0.94, \mathrm{I} .13)$ & 0.536 \\
Previous dementia diagnosis & $0.7 \mathrm{(I}(0.09,5.99)$ & 0.756 \\
MoCA & $0.93(0.85, \mathrm{I} .02)$ & 0.112 \\
CIB & $0.72(0.60,0.87)$ & $0.00 \mathrm{I}$ \\
$\quad$ CIB Working Memory & $0.64(0.47,0.89)$ & 0.008 \\
CIB Planning/Organization & $0.53(0.37,0.77)$ & $0.00 \mathrm{I}$ \\
ADL impairment & $3.73(\mathrm{I} .54,9.03)$ & 0.003 \\
IADL impairment & $\mathrm{I} .74(0.85,3.60)$ & 0.132 \\
\hline
\end{tabular}

Abbreviations: $\mathrm{ADL}$, activities of daily living; $\mathrm{Cl}$, confidence interval; $\mathrm{CIB}$, Clockin-the-Box; IADL, instrumental activities of daily living; MoCA, Montreal Cognitive Assessment; OR, odds ratio.

$95 \% \mathrm{CI}=0.58-0.95, P=0.0016$ ), were significantly associated with discharge to location other than home. In a separate regression, ADL function $(\mathrm{aOR}=0.74,95 \% \mathrm{CI}=0.59-0.95$, $P=0.016$ ), but not z-transformed MoCA score (aOR $=0.84$, $95 \% \mathrm{CI}=0.56-1.25, P=0.389$ ), was significantly associated with discharge to a location other than home. Inclusion of CIB total score, ADL score, and MoCA score, adjusting for age and race, revealed that only CIB total score $(\mathrm{aOR}=0.55$, $95 \% \mathrm{CI}=0.36-0.83, P=0.004)$ and ADL score were significantly associated with discharge to a location other than home $(\mathrm{aOR}=0.733,95 \% \mathrm{CI}=0.57,0.94, P=0.014)$ (Table 3$)$.

We were also interested in examining the association between CIB subscales on discharge to a location other than home. Multivariate logistic regression, adjusting for age and race, revealed that the Planning/Organization subscale score and the ADL score were associated with discharge to a location other than home $(\mathrm{aOR}=1.61,95 \% \mathrm{CI}=1.00-2.60$ and $\mathrm{aOR}=1.34,95 \% \mathrm{CI}=1.04-1.71$, respectively) (Table 3 ).

\section{Discussion}

In an aging society and a changing health care system, there is an increased focus on patients returning to their home environment following hospitalization. However, returning home for individuals with cognitive impairment has been associated with increased rates of readmission and associated costs, within 1 month. ${ }^{24}$ Accurate identification of individuals with
Table 3 Multivariable models predicting discharge to location other than home

\begin{tabular}{|c|c|}
\hline & $\begin{array}{l}\text { Adjusted odds } \\
\text { ratio }(95 \% \mathrm{Cl})\end{array}$ \\
\hline \multicolumn{2}{|l|}{ Model \#I CIB total score } \\
\hline Age (per year) & $1.00(0.97,1.05)$ \\
\hline Non-White race & $1.19(0.58,2.42)$ \\
\hline CIB total score (per SD unit decline) & $0.59(0.4 \mathrm{I}, 0.84)^{* * *}$ \\
\hline Activities of Daily Living (per point decline) & $0.74(0.58,0.95)^{* * *}$ \\
\hline \multicolumn{2}{|l|}{ Model \#2 MoCA total score } \\
\hline Age (per year) & $1.02(0.98,1.07)$ \\
\hline Non-White race & $1.25(0.63,2.46)$ \\
\hline MoCA (per SD unit decline) & $0.84(0.59,1.25)$ \\
\hline Activities of Daily Living (per point decline) & $0.74(0.59,0.95)^{*}$ \\
\hline \multicolumn{2}{|l|}{ Model \#3 CIB total score with MoCA } \\
\hline Age (per year) & $1.01(0.97,1.06)$ \\
\hline Non-White race & $1.16(0.57,2.37)$ \\
\hline CIB total score (per SD unit decline) & $0.55(0.36,0.83) * *$ \\
\hline MoCA (per SD unit decline) & $1.17(0.73,1.90)$ \\
\hline Activities of Daily Living (per point decline) & $0.73(0.57,0.94)^{*}$ \\
\hline \multicolumn{2}{|l|}{ Model \#4 CIB subscales } \\
\hline Age (per year) & $1.00(0.97,1.05)$ \\
\hline Non-White race & $1.20(0.58,2.45)$ \\
\hline $\begin{array}{l}\text { CIB Working Memory subscale } \\
\text { (per SD unit decline) }\end{array}$ & $0.86(0.56,1.32)$ \\
\hline $\begin{array}{l}\text { CIB Planning/Organization subscale } \\
\text { (per SD unit decline) }\end{array}$ & $0.63(0.40,1.00)^{*}$ \\
\hline Activities of daily living (per point decline) & $0.75(0.58,0.96)^{*}$ \\
\hline
\end{tabular}

Notes: $* P<0.05 ; * * P<0.01$.

Abbreviations: $\mathrm{Cl}$, confidence interval; $\mathrm{ClB}$, Clock-in-the-Box; MoCA, Montreal Cognitive Assessment; SD, standard deviation.

cognitive impairment remains a critical aspect in reducing the inappropriate discharge of individuals to home.

This study found that cognitive performance, as measured by the CIB independently as well as in conjunction with prehospitalization ADL functioning, was associated with discharge to locations other than home following hospitalization, even after adjusting for relevant demographics. Specifically, every standardized unit increase on the CIB was associated with a reduction in the odds of discharge to a location other than home, after adjusting for demographics, MoCA score, and ADL functioning. This finding complements earlier evidence indicating that cognitive impairment during hospitalization may be associated with adverse outcomes. ${ }^{5}$ Also, the finding that the CIB Planning/Organization subscale score is associated with discharge home is consistent with previous literature highlighting the relationship between higher-order executive functioning abilities and the ability to return home after hospitalization. ${ }^{11}$ Collectively, these findings support the use of the CIB as a cognitive screening measure with hospitalized older adults.

Strengths of the current study included the use of the CIB, a brief and easy-to-use cognitive screening measure. 
The various causes of admission within this patient sample are also a significant strength, as this sample of patients is highly similar to the actual inpatient populations. Consequently, the strong association between CIB score and discharge to location other than home within this sample suggests that the CIB has applicability within a wide range of patient populations admitted to a tertiary care setting. A limitation of the current study was the use of a single-site, and a predominantly male, Caucasian, and well-educated sample, which may reduce generalizability. The CIB demonstrates good performance across the dynamic range of the Mini Mental State Examination and the MoCA, but like most rapid cognitive screening assessments, is challenged by ceiling and floor effects.

\section{Conclusion}

The current study supports the use of the CIB as a cognitive screen for inpatient older adults. Future studies examining the predictive ability of the CIB on the cognitive and functional outcomes beyond hospital discharge (eg, future cognitive decline, impairments in ADL) will be useful in further exploring its applications. However, given the current evidence within an older adult inpatient sample, the CIB has demonstrated strong utility as a brief cognitive screen, particularly to identify those who will not return home after hospitalization.

\section{Acknowledgments}

We are indebted to the Veterans who participated in our delirium and fall reduction programs. We are thankful for the guidance of the Department of Veterans Affairs (VA) Boston Healthcare System (VABHS) Boston Delirium Task Force, and Patient Safety Officers for their continued collaboration to improve the outcomes for the Veterans we serve. The Clock-in-the-Box was developed by Dr Grande, with contributions from Dr Milberg. All authors were VA employees at that time.

Support for this study was provided by the Delirium Patient Safety Center of Inquiry from the VA Office of Patient Safety. The funders had no influence in the conduct, analysis, or interpretation of the study data.

Dr Jackson was funded by a VA Fellowship in Advanced Geriatrics. Dr Rudolph is supported by the VA Health Services Research and Development Center of Innovation in Long Term Services and Supports (CIN 13-419) and the VA QUERI- Geriatrics and Extended Care Partnered Evaluation Center for Community Nursing Homes (PEC 15-465). The views expressed here are the opinion of the authors and do not represent the official policy of the VA.

\section{Author contributions}

All authors had access to the data and played a role in writing this manuscript. JLR contributed to the study design; $\mathrm{KD}, \mathrm{EA}, \mathrm{BK}$, and JLR contributed to the acquisition of data; JLR participated in data analysis; CEJ, JLR, LJG, JAD, and WPM were involved in data interpretation; and CEJ, LJG, $\mathrm{KD}, \mathrm{EA}, \mathrm{BK}$, WPM, and JLR were involved in preparation of the manuscript. All authors contributed toward data analysis, drafting and revising the paper and agree to be accountable for all aspects of the work.

\section{Disclosure}

The authors report no conflicts of interest in this work.

\section{References}

1. Gill TM, Allore HG, Gahbauer EA, Murphy TE. Change in disability after hospitalization or restricted activity in older persons. JAMA. 2010;304(17):1919-1928.

2. Bachmann S, Finger C, Huss A, Egger M, Stuck AE, Clough-Gorr KM Inpatient rehabilitation specifically designed for geriatric patients: systematic review and meta-analysis of randomised controlled trials. BMJ. 2010;340:c1718.

3. Campbell SE, Seymour DG, Primrose WR. A systematic literature review of factors affecting outcome in older medical patients admitted to hospital. Age Ageing. 2004;33(2):110-115.

4. Hustey FM, Meldon SW, Smith MD, Lex CK. The effect of mental status screening on the care of elderly emergency department patients. Ann Emerg Med. 2003;41(5):678-684.

5. Boustani M, Baker MS, Campbell N, et al. Impact and recognition of cognitive impairment among hospitalized elders. J Hosp Med. 2010;5(2):69-75.

6. Torisson G, Minthon L, Stavenow L, Londos E. Cognitive impairment is undetected in medical inpatients: a study of mortality and recognition amongst healthcare professionals. BMC Geriatr. 2012;12:47.

7. Zhu CW, Cosentino S, Ornstein K, Gu Y, Andrews H, Stern Y. Use and cost of hospitalization in dementia: longitudinal results from a communitybased study. Int J Geriatr Psychiatry. 2015;30(8):833-841.

8. Harrington MB, Kraft M, Grande LJ, Rudolph JL. Preoperative cognitive status is independently associated with discharge location after cardiac surgery. Am J Crit Care. 2011;20(2):129-137.

9. Barnes DE, Mehta KM, Boscardin WJ, et al. Prediction of recovery, dependence or death in elders who become disabled during hospitalization. J Gen Intern Med. 2013;28(2):261-268.

10. Ismail Z, Rajji TK, Shulman KI. Brief cognitive screening instruments: an update. Int J Geriatr Psychiatry. 2010;25(2):111-120.

11. Razani J, Casas R, Wong JT, Lu P, Alessi C, Josephson K. Relationship between executive functioning and activities of daily living in patients with relatively mild dementia. Appl Neuropsychol. 2007;14(3): 208-214.

12. Grande L, Milberg W, Rudolph J, Gaziano M, McGlinchey R. A timely screening for executive functions and memory. J Int Neuropsychol Soc. 2005;11:9-10

13. Chester JG, Grande LJ, Milberg WP, McGlinchey RE, Lipsitz LA, Rudolph JL. Cognitive screening in community-dwelling elders: performance on the clock-in-the-box. Am J Med. 2011;124(7):662-669.

14. Grande LJ, Rudolph JL, Milberg WP, Barber CE, McGlinchey RE. Detecting cognitive impairment in individuals at risk for cardiovascular disease: the "Clock-in-the-Box" screening test. Int J Geriatr Psychiatry. 2011;26(9):969-975.

15. Helvik AS, Skancke RH, Selbaek G, Engedal K. Nursing home admission during the first year after hospitalization - the contribution of cognitive impairment. PLoS One. 2014;9(1):e86116. 
16. Charlson ME, Pompei P, Ales KL, MacKenzie CR. A new method of classifying prognostic comorbidity in longitudinal studies: development and validation. J Chronic Dis. 1987;40(5):373-383.

17. Sheikh JI, Yesavage JA. Geriatric Depression Scale (GDS): Recent Evidence and Development of a Shorter Version. New York: The Haworth Press; 1986.

18. Katz S. Assessing self-maintenance: activities of daily living, mobility, and instrumental activities of daily living. J Am Geriatr Soc. 1983; 31(12):721-727.

19. Lawton MP, Brody EM. Assessment of older people: self-maintaining and instrumental activities of daily living. Gerontologist. 1969;9(3): 179-186.

20. Spector WD, Katz S, Murphy JB, Fulton JP. The hierarchical relationship between activities of daily living and instrumental activities of daily living. J Chronic Dis. 1987;40(6):481-489.
21. Nasreddine ZS, Phillips NA, Bédirian V, et al. The montreal cognitive assessment, MoCA: a brief screening tool for mild cognitive impairment. J Am Geriatr Soc. 2005;53(4):695-699.

22. Munshi M, Grande L, Hayes M, et al. Cognitive dysfunction is associated with poor diabetes control in older adults. Diabetes Care. 2006;29(8):1794-1799.

23. StataCorp. Stata Statistical Software: Release 11. College Station, TX: StataCorp LP; 2009.

24. Tropea J, LoGiudice D, Liew D, Gorelik A, Brand C. Poorer outcomes and greater healthcare costs for hospitalised older people with dementia and delirium: a retrospective cohort study. Int $J$ Geriatr Psychiatry. Epub 2016 Apr 25. 


\section{Supplementary materials}

Table SI Age and education normative values for CIB total score

\begin{tabular}{lllll}
\hline Years of education & Age 55-64 years & Age 65-74 years & Age 75-84 years & Age $\geq 85$ years \\
\hline$<12$ years, $M(S D)$ & $5.4(I .7)$ & $5.1(1.4)$ & $4.4(I .9)$ & $3.2(2.1)$ \\
$\mathrm{n}$ & 7 & $\mathrm{II}$ & 13 & 6 \\
High school graduate, $M(\mathrm{SD})$ & $5.4(2.1)$ & $5.4(1.9)$ & $4.9(1.7)$ & $2.8(2.0)$ \\
$\mathrm{n}$ & 18 & 17 & 12 & 6 \\
$>12$ years, $M(\mathrm{SD})$ & $6.5(1.4)$ & $6.2(1.0)$ & $5.2(1.5)$ & $5.7(1.1)$ \\
$\mathrm{n}$ & 47 & 47 & 34 & 7 \\
\hline
\end{tabular}

Abbreviations: CIB, Clock-in-the-Box; M, mean; SD, standard deviation.

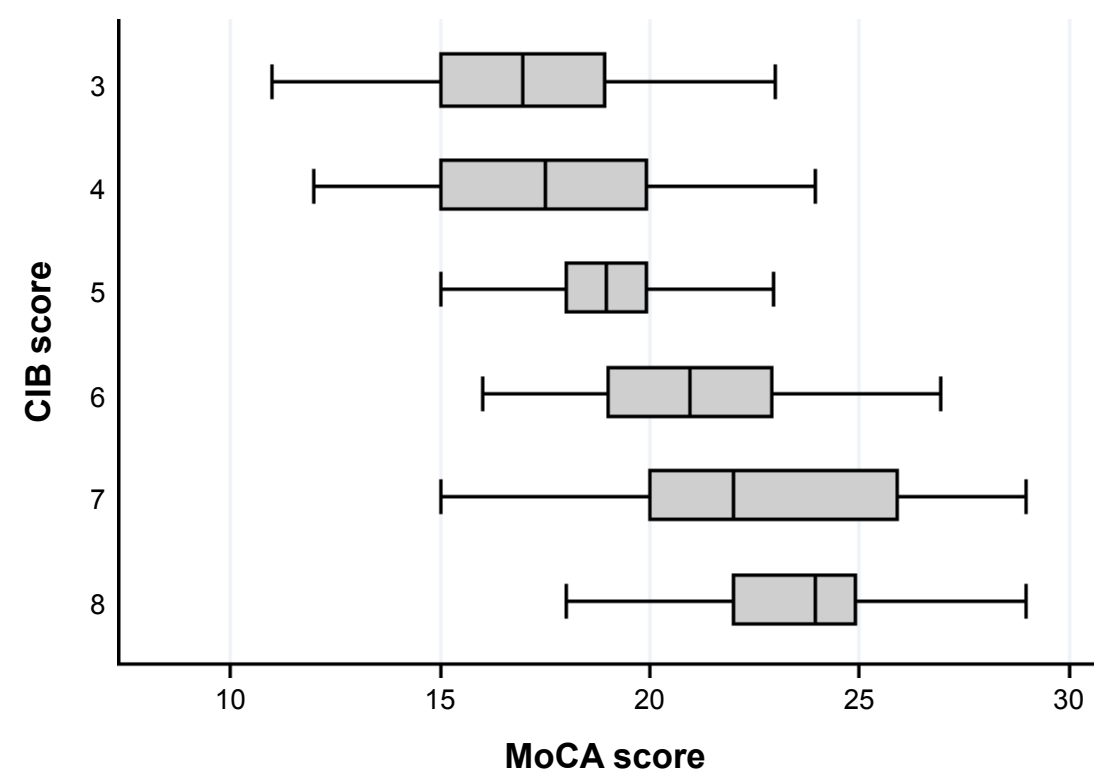

Figure SI Relation between CIB total score and MoCA score.

Notes: Median, 25th, and 75th percentiles are indicated by the box; range is displayed by the bars.

Abbreviations: $\mathrm{CIB}$, Clock-in-the-Box; MoCA, Montreal Cognitive Assessment.

Clinical Interventions in Aging

\section{Publish your work in this journal}

Clinical Interventions in Aging is an international, peer-reviewed journal focusing on evidence-based reports on the value or lack thereof of treatments intended to prevent or delay the onset of maladaptive correlates of aging in human beings. This journal is indexed on PubMed Central, MedLine,
CAS, Scopus and the Elsevier Bibliographic databases. The manuscript management system is completely online and includes a very quick and fair peer-review system, which is all easy to use. Visit http://www.dovepress. com/testimonials.php to read real quotes from published authors. 